\title{
AS CONTRIBUIÇÕES A PARTIR DO OLHAR ATENTO: ESTUDOS DO MEIO E A EDUCAÇÃO PARA A VIDA*
}

\author{
Contributions of attention: studies of the environment \\ and education for life
}

\author{
Sandra Lestinge ${ }^{1}$ \\ Marcos Sorrentino ${ }^{2}$
}

\begin{abstract}
Resumo: $\mathrm{O}$ presente artigo tem por finalidade apresentar alguns autores que dão ênfase à utilização de atividades de campo dirigidas, realizadas em ambiente extraclasse, aqui denominadas de estudos do meio; contextualizando-as, criticamente, como possível contribuição frente à crise de percepção vivida na contemporaneidade. Apesar de não estar restrito apenas à comunidade escolar ou ao ensino formal, é como recurso didático que o estudo do meio é valorizado, devido aos resultados expressivos - pois imprime qualidade - nas relações de ensino-aprendizagem, interpessoais e intrapessoais. A percepção sobre o cotidiano, a realidade social, cultural, histórica, do meio físico e natural foi e ainda é fundamental no processo de formação do cidadão emancipado e compromissado; e, deve ser uma prática constante para nortear as sociedades da "era do conhecimento" rumo à construção de saberes para a sustentabilidade socioambiental e melhoria da qualidade de vida.
\end{abstract}

Palavras-chave: Ensino-aprendizagem. Educação ambiental. Percepção. Estudo do meio.

\begin{abstract}
The objective of the present article is to present some authors who emphasize the utilization of field-based activities, performed in out-of-the-class contexts, here called studies of the environment, placing them, critically, in context, as a possible contribution vis-à-vis the crisis of perception we are facing today. While it is not restricted solely to the schooling community or to the formal teaching, it is as a didactical resource that the study of the means is valued, owing to the outstanding results - since it applies quality to - in the teaching-learning, interpersonal and intrapersonal relationships. The perception on the day-to-day, the social, cultural and historical reality of the physical and natural environment was and still is crucial to the process of formation of the independent and committed citizen; and it must be a constant practice guiding societies in the era of knowledge, towards construction of knowledge for socioenvironmental sustainability and quality of life improvement.
\end{abstract}

Keywords: Teaching-learning. Environmental education. Perception. Studies of the environment.

* Elaborado a partir de Lestinge (2004).

${ }^{1}$ Zootecnista. Doutora em Recursos Florestais. Docente visitante, Universidade de Brasília, Centro de Educação a Distância (CEAD). Brasília, DF. < sandra.lestinge@cead.unb.br>

${ }^{2}$ Biólogo e Pedagogo. Pós-doutorado em Educação. Diretor do Departamento de Educação Ambiental, Ministério do Meio Ambiente. Brasília, DF. <marcos.sorrentino@mma.gov.br>

${ }^{1}$ SQN 111, Bloco H, apto. 302

Asa Norte - Brasília, DF

70.754-080 


\section{Estudos do meio para compreensão da realidade}

La vida urbana, e incluso la vida en el campo, cada vez más mecanizada, nos alejan del mundo físico y vivo; nos sumergem en el medio artificial de nuestras creaciones. Pronto seremos incapaces de imaginar las noches sin luz, el aire sin ruido y olor a petróleo, el espacios sin cubos de geometría cuyos únicos vacíos los llena una humanidad aglomerada. El tiempo sometido a la velocidad ya no tiene duración...toda interrupción de las leyes naturales en este mundo artificial, que el hombre cree falsamente dominar con sus técnicas, sorprende y escandaliza. (DEBESSE-ARVISET, 1985, p. 170)

O caminho para se encontrar soluções para os problemas complexos vividos na atualidade - como os consecutivos alarmes sobre as conseqüências do desmatamento das florestas tropicais e sobre o aquecimento global - requer uma visão complexa, como indica Morin (2003), compartilhada sobre a realidade, e não compartimentada. É este percurso que o presente artigo irá trilhar: como um estudo do meio pode impregnar de conhecimento, valores e sentimentos aqueles que se dispõem à imersão e à reflexão com base nas experiências vividas.

Pretende-se, também, provocar no leitor algumas reflexões sobre o modo pelo qual nos relacionamos com o entorno: da epiderme ao cosmo. Instigar à reflexão sobre como está a qualidade do olhar, do ouvir, do cheirar, do sentir, do perceber, do tocar, do falar, do calar. Será que a realização de estudos do meio pode ampliar nossos horizontes, fazendo-nos sentir (mais) pertencentes à vida, ao mundo? É possível determinar se, no processo da civilização ocidental, houve alguns momentos históricos de "ruptura" que distanciaram o ser humano dos rios, das terras, vales e montanhas, do prazer dos ventos, do medo dos furacões e avalanches, do aprendizado na/e da natureza?

Numa tentativa de responder a essas questões, conclui-se que vivemos numa grave crise de percepção, e segundo Capra (1996), vive-se num estado de desconexão com a realidade espaço-temporal, associada à dificuldade de se consolidar políticas públicas com foco social e ambiental que busquem soluções responsáveis (preventivas, mitigadoras e compensatórias) para os desastres socioambientais, descritos exaustivamente pelo movimento ambientalista desde a década de 1960.

Presencia-se, no início do século XXI, uma relação desigual, conflitante e ameaçadora entre o ser humano e a natureza, pois o que ainda prevalece é uma visão mercantilista e insustentável sobre os recursos não renováveis que são explorados e usados como se fossem fontes inesgotáveis que servem à demanda crescente de energia e de bens de consumo.

Há uma inegável pressão econômica vinda de um mercado produtor que impulsiona uma pequena parcela privilegiada da população a consumir muito mais a cada instante, sem tempo e espaço para se discutirem as consequências deste tipo de consumo, e nem mesmo questionar as necessidades reais de tamanha diversidade de bens, além dos destinos dos resíduos que se produzem diariamente nas cidades mais industrializadas do planeta.

A busca frenética por bens de consumo impulsiona, também, o conhecimento científico e tecnológico para que tragam luz a questões recorrentes. Para isso, investem-se quanti- 
dades expressivas de "tempo e dinheiro" na tentativa de se encontrarem respostas sobre a origem da vida no planeta, dos seres humanos e a busca pelo "elo perdido"; as fontes de energia possíveis de substituir os combustíveis fósseis, e tantas outras questões. "Los héroes ya no son Cristóbal Cólon, Amundsen o Scott, sino los astronautas. Se ha trastornado un mundo" (DEBESSE-ARVISET, 1985, p. 155).

Sabe-se, por exemplo, que algumas combinações de gases e partículas em suspensão na atmosfera são co-responsáveis pela manutenção das condições da vida humana, vegetal e animal no planeta. Os processos físicos, químicos, geológicos e biológicos que nos envolvem são bastante dinâmicos; porém, o conhecimento até hoje acumulado sobre essas correlações, são insuficientes para compreender as repercussões das ações antrópicas sobre os diferentes níveis de interação ser humano/natureza. O aquecimento global é uma das provas de que as justificativas às repercussões vividas podem transitar desde as explicações de ser este um fenômeno natural até o fato de resultar da intensa atividade humana desde a era industrial.

Nessa situação, podem-se considerar ainda dois agravantes: o distanciamento cognitivo e sensorial do entorno, do cotidiano, do saber empírico; e as evidências das restrições de acesso ao conhecimento científico e às novas tecnologias às "pessoas comuns". Isto nos distancia da nossa própria vida, do mundo que nos cerca, das possibilidades de inferir e interferir nele.

Esse é um dos fatores que contribui para o distanciamento do ser humano (devido ao distanciamento dos sentidos) da sua realidade cotidiana, do meio em que vive. É relevante perceber a realidade socioambiental e a paisagem para que um projeto ou ação seja qualificado/referendado pelos atores envolvidos e reconhecido por uma comunidade. É preciso olhar, ouvir, sentir, refletir, pensar e participar os sujeitos para que todos se percebam pertencendo àquele grupo e, assim, conhecer para estabelecer co-responsabilidades perante as problemáticas socioambientais da contemporaneidade.

Para Carlos Rodrigues Brandão, o conhecimento é uma gama de diferentes formas e dimensões do saber humano. "De qualquer maneira e sempre é preciso conhecer. Será preciso, o tempo todo, estar realizando a ousadia e o esforço de adquirir mais e melhor conhecimento" (BRANDÃO, 1997, p. 18). Nesse sentido o estudo do meio será tratado aqui numa perspectiva de contribuir para o reconhecimento da realidade ${ }^{3}$, pois propicia reflexões e conhecimentos; desperta sensações e sentimentos que poderão potencializar/alavancar ações humanas em prol de melhoria na qualidade de vida.

É difícil precisar desde quando se realizam atividades de campo com finalidade didática, mas seguramente esse tipo de atividade vem de muito tempo, de décadas e, mesmo, de séculos atrás. No entanto ela é praticada em algumas escolas ainda hoje, mesmo que aquém do desejado pelos estudantes, que em geral se interessam por aulas em espaços diferenciados. Existe aí um ponto de tensão entre a oferta que é feita pelas escolas e educadores e a demanda

\footnotetext{
${ }^{3}$ Considera-se, aqui, realidade, numa perspectiva de compreender, transformar, intervir para a emancipação social.
} 
dos educandos por um ensino melhor, que faça referência à realidade contemporânea, sobretudo aos temas ligados à questão ambiental.

Um estudo do meio é comumente conhecido como uma atividade dirigida em que se utiliza determinado local/entorno/paisagem para se aprofundarem conceitos e/ou conteúdos geralmente relacionados ao currículo escolar. Para que as vivências atinjam as expectativas dos participantes, e, conseqüentemente, para que haja êxito enquanto proposta pedagógica, todas as etapas devem ser previamente planejadas e detalhadas, pois são muitas as variáveis que interferem na realização: o interesse/envolvimento das pessoas, as condições no local escolhido (climáticas, segurança, transporte, alimentação), a duração de cada uma das atividades no campo, o preparo (teórico e prático) dos condutores/professores/guias entre outros.

São múltiplas as contribuições que poderão advir da realização dos estudos do meio. Uma delas é pela aproximação das pessoas participantes, nas relações intra e interpessoais; que, apesar de ser fundamental - o viver em grupo - como exercício de convivência, em geral, fica em segundo plano ou é subestimado quando prepondera a visão cartesiana, ou seja, de um aprendizado mecanicista.

No entanto, durante as atividades, o foco deve ser dirigido para as possibilidades de ensino-aprendizagem por meio da observação, percepção, interpretação e análise dos dados coletados em busca de conhecimento e compreensão contextualizada sobre o meio em que se vive - numa seqüência planejada que produza maravilhamento, prazer em estar junto, em desfrutar de uma viagem e/ou da companhia dos colegas.

Pois, apesar dos avanços científicos, quanto conhecemos do ambiente natural? Quantos de nós (e quantas vezes) paramos para pensar que as condições aprazíveis (mesmo que aparentemente inóspitas de algumas regiões extremas) que se tem neste planeta são as bases para a magnífica diversidade de espécies vegetais e animais, muitas ainda desconhecidas? Apesar de geralmente dar-se ênfase à biodiversidade, sabe-se que há associações importantes também entre as grandes massas de água, os ventos e o clima. Deve-se ressaltar que todos esses sistemas estão interligados e são interdependentes.

Mas houve um tempo em que o conhecimento, mesmo que empírico, pertencia ao "homem comum". Sabia-se, por exemplo, as mudanças das estações ou o rigor de um inverno pelas formas e/ou cores das nuvens, pela direção dos ventos ou migração de animais. Não se quer dizer com isso que este "tempo pretérito" tenha se perdido totalmente, mas muitos conhecimentos tradicionais e empíricos se perderam sim com o extermínio das nações indígenas do Brasil e de outros povos e culturas da América Latina.

Boaventura de Sousa Santos faz uma crítica que é convergente a essa problemática quando afirma que "a ciência moderna desconfia sistematicamente das evidências da nossa experiência imediata" (SANTOS, 2002, p. 12), isto é, o conhecimento científico faz um desvendamento da natureza que não é contemplativo, e sim ativo, pois visa conhecer a natureza para subordiná-la às necessidades e vontades humanas.

O que se foi, ou parece que se perdeu em grande parte, é a capacidade de se perceberem e desvendarem os sinais. Perdeu-se o "tempo" necessário para a observação, leitura, reconhecimento e compreensão do entorno. Perdeu-se também o "tempo" da fruição, do devaneio, do deleite ou do contemplativo, pois se visa "conhecer a natureza para a dominar e controlar" (SANTOS, 2002, p. 13). É como se uma estrutura gigante, invisível, impusesse um novo continuum, uma nova velocidade e ritmo, gerando uma outra qualidade da relação, 
distanciando as impressões internas e externas da consciência reflexiva sobre elas, do corpóreo humano. "A cada dia se passam muitas coisas, porém, ao mesmo tempo, quase nada nos acontece" (BONDÍA, 2001, p. 2).

Os seres humanos já estiveram mais conectados/ligados à realidade (pelo menos local) pela própria necessidade de sobrevivência. Desde os primórdios, os habitantes das cavernas - coletores e depois caçadores - tinham os sentidos aguçados pela necessidade de sobrevivência; porém atualmente parece haver um "sedentarismo" causado pelo modo de vida contemporâneo, anestesiando-nos pelo conforto proporcionado pela utilização de computadores, televisores, supermercados. Conforme Hillman (1993), temos poucas surpresas ao caminhar pelas ruas dos grandes centros urbanos, além do estresse causado pela violência, poluição. Os sentidos se embotam, distanciando-nos da possibilidade de nos apropriarmos de algo que também nos pertence e da qual fazemos parte - a Terra ${ }^{4}$.

Os estudos do meio realizados em áreas naturais, numa perspectiva de compreender a complexidade humana (MORIN, 2000), que explore e respeite as sensações/percepções (frio, calor, desconforto, cansaço, prazer etc) pode levar ao conhecimento, modificações e autoconhecimento, revelando o sentimento de pertença; pois "ao ampliar a noção de si mesmo, o mundo também se amplia” (MENDONÇA, NEIMAN, 2003, p. 81).

\section{Teoria e prática rumo à uma escola viva}

Não estou fazendo esta maravilhosa viagem com o propósito de me iludir, mas sim de me conhecer melhor a partir dos objetos que vejo (GOETHE, 1999, p. 53-4).

Pode-se afirmar que, na atualidade, há um distanciamento da "realidade vivida", fato este atribuído à velocidade do modo de vida contemporâneo; e, em conseqüência disso, a compreensão e a "apropriação" do cotidiano, nos diferentes segmentos sociais, perde qualidade, sobretudo nas escolas, onde deveria se dar o inverso, pela somatória de projetos, ações, discussões e reflexões próprias da atividade pedagógica.

Práticas que se destinem à resolução de problemas (OTT, 1989) e à compreensão da realidade (NIDELCOFF, 1979), entre outras, deveriam ser constantemente estimuladas no âmbito do ensino formal e do informal. A comunidade escolar, em geral, parece desconsiderar a perda paulatina do contato lúdico e da compreensão que se tem do ambiente mais próximo, o entorno. Carvalho (2001) afirma que antes das 'Educações Ambientais', outras correntes pedagógicas também se preocuparam em contextualizar os sujeitos em seu entorno histórico,

\footnotetext{
${ }^{4}$ Referência a duas idéias: a da hipótese de Gaia, mais difundida por James Lovelock e Lynn Margulis, como "um complexo entrelaçamento de sistemas vivos e não-vivos dentro de uma única teia" (CAPRA, 1996, p. 173-4); e a de Serres (1994), segundo a qual o homem deve buscar um estado de "paz e o amor", e para tal deve renunciar ao contrato social primitivo, firmando um novo pacto com o mundo - o contrato natural.
} 
social e natural. Para ele, trabalhos de campo, estudos do meio, temas geradores, aulas ao ar livre, não são atividades inéditas na Educação. Tomados cada um por si, esses recursos educativos não são estranhos às metodologias consagradas na educação como aquelas inspiradas em Paulo Freire e Piaget, entre outras (CARVALHO, 2001).

Nesse sentido, Carvalho (2001) comenta que caberia à educação ambiental a revisita desse conjunto de atividades pedagógicas, atualizando-as dentro de um novo horizonte epistemológico onde o ambiental é pensado como sistema complexo das relações e interações da base natural e social.

A escola, como espaço de formação crítica, deveria promover constantemente práticas educativas voltadas à conscientização da problemática socioambiental e conseqüente busca de soluções. Bondía (2001, p. 5) comenta que o sujeito moderno

além de ser um sujeito informado que opina, além de estar permanentemente agitado e em movimento, é um ser que trabalha, tanto o mundo "natural" quanto o mundo "social" e "humano", tanto a "natureza externa" quanto a "natureza interna", segundo o seu saber, seu poder e sua vontade. (BONDÍA, 2001, p. 5)

Com foco na realidade escolar, o autor coloca que "na escola o currículo se organiza em pacotes cada vez mais numerosos e cada vez mais curtos. Com isso, também em educação estamos sempre acelerados e nada nos acontece" (BONDÍA, 2001, p. 4). Essa crítica remete a uma problemática sobre o volume de informações e áreas de conhecimento a que se está exposto (nos bancos escolares e além deles) e que se tem à disposição; permite uma experiência verdadeira - que nos passa, que nos acontece, que nos toca - durante o processo educativo.

Cada vez estamos mais tempo na escola [...] mas cada vez temos menos tempo. Esse sujeito da formação permanente e acelerada, da constante atualização, da reciclagem sem fim, é um sujeito que usa o tempo como um valor ou uma mercadoria, um sujeito que não pode perder tempo (BONDÍA, 2001, p. 4).

Então, na busca por respostas às perguntas iniciais, mais abrangentes (e que remetem ao passado ou ao futuro), há também outros questionamentos primordiais, não menos importantes, como, por exemplo: Quem sou? Onde estou? Para onde quero prosseguir? Certamente o corre-corre da "vida moderna", dos grandes centros urbanos, tem contribuído para que não se pense nisso, para que não se busquem respostas ou, até, que não se façam tais perguntas.

A alienação pode ser mantida e estimulada por um modo de vida consumista, "fast food", perdendo-se o olhar atencioso e reflexivo para si próprio e para o outro. Como contrapartida, poderia se promover um modo de vida baseado no "slow food", um movimento internacional, que nasceu na Itália e que promove uma educação do paladar, resgatando-se sabores e saberes, em contraposição ao modo de vida alienante que predomina em várias sociedades do mundo. 
Ragionare sul piacere che questo mondo ci può dare non può prescindere dal ragionare sulla necessità di mantenere un equilibrio di rispetto e di scambio con la natura, con l'ambiente. Ecco perché ci piace definirci "ecogastronomi". Siamo sicuri che il nostro piacere non può non essere legato al piacere degli altri, ma allo stesso modo è legato all'equilibrio che sapremo mantenere (e in molti casi ritrovare) con l'ambiente che ci ospita ${ }^{6}$. <http://www.slowfood.it/ita/sf_cose/ sf_cose.lasso>

Essa perspectiva, que valoriza a alimentação "consciente", não só como uma necessidade básica de todo ser humano, mas também como um hábito cultural ou um modo de vida mais saudável, faz pensar sobre o acesso à qualidade e à quantidade de alimentos, que é bastante desigual entre os hemisférios norte e sul do planeta, refletindo diretamente nas condições de vida das populações. Na última década, por exemplo, o governo dos Estados Unidos tem alertado sobre as doenças causadas pelo sedentarismo e obesidade da população norteamericana, pois ela consome, em excesso, alimentos industrializados (de má qualidade).

Para usufruir a vida em sociedade, deve-se promover a aproximação do sujeito com as coisas e acontecimentos, mas não aleatoriamente, e sim conjugadas com atenção, paciência e tolerância. Para isso, pressupõe-se a valorização de uma característica da pessoa humana: a de ser "um ente associativo, porque o ser humano não existe sozinho" (DALLARI, 2001, p. 86). Dallari afirma que é uma característica humana viver em associações na busca por modos de convivência; e, é na busca por regras de convivência que contribuam para uma harmonia social, e na fixação destas regras, que a participação passa a ser não só um direito, mas um dever que não se pode deixar de cumprir.

É a partir deste cenário, com ênfase também na necessidade de participação dialógica e potencializadora de ações críticas e reflexivas, que se pretende incentivar mais e melhores iniciativas de realização de estudo do meio $^{7}$, pois no cotidiano e na comunidade escolar há oportunidade, num ambiente profícuo, de se fomentarem experiências que contribuam para a aprendizagem de crianças, adolescentes e adultos, pois:

A escola tem que ajudar a criança para que, em seu processo de crescimento, ela vá compreendendo a realidade que a cerca e nela vá se localizando lúcida e criativamente. Este processo a inicia na reali-

\footnotetext{
${ }^{5}$ Conforme consta no site italiano http://www.slowfood.it/ (mai/2004), sobre gastronomia, "slow food" se contrapõe à tendência de "estandarização/padronização" do gosto, defendendo a necessidade de informação da parte do consumidor do mundo.

6 "Pensar sobre o prazer que este mundo pode nos dar não pode estar desvinculado do pensar sobre a necessidade de manter um equilíbrio de respeito e de troca com a natureza, com o ambiente. Eis por que gostamos de nos definir "ecogastrônomos". Temos certeza de que o nosso prazer não pode não estar unido ao prazer dos outros, mas, ao mesmo tempo, está unido/ligado ao equilíbrio que saberemos manter (e, em muitos casos, reencontrar) com o meio que nos acolhe".
} 
dade imediata com o meio: aprende a VER no mesmo, para em seguida estender seu olhar na direção de horizontes mais largos (NIDELCOFF, 1979, p. 11).

Método, técnica, atividade de campo, aula prática, excursão, vivência ou outra nomenclatura que o identifique, destaca-se a importância de se criar "elos" ou "pontes" que instiguem a proposição e realização de estudo do meio numa perspectiva de contribuir para a construção de sociedades mais justas e igualitárias, ressaltando-se o "contexto político da relação educativa" (DEMO, 2002, p. 91).

A utilização do estudo do meio $^{8}$ como metodologia para a educação ambiental pode contribuir para uma formação mais "integral" do indivíduo, quando se propõe um olhar cuidadoso e atento para o que está à volta, para a compreensão e discussão da realidade e do entorno, por intermédio de projetos interdisciplinares e integrados.

A partir daí, deste reconhecimento, acredita-se poder inferir que sujeitos sociais distintos se potencializem para ações que sejam mais responsáveis no tocante à questão ambiental. Pontuschka (1994) destaca a importância de se definir o que se entende por estudo do meio uma "prática social" - com base em trabalhos realizados "no passado até nossos dias".

\section{Educação ambiental na escola}

Para que um estudo do meio seja caracterizado como atividade de educação ambiental, ele precisa estar em consonância com um pensamento mais complexo sobre "meio ambiente". Parece haver um consenso, entre alguns autores, de que a educação ambiental tenha um caráter além do relativo (separação do "lixo", reciclagem), mas uma intenção maior de politizar e capacitar cidadãos e cidadãs a tomarem posicionamentos, por exemplo, sobre os altos padrões de consumo de países industrializados do hemisfério norte e a sustentabilidade do planeta. Assim, Freire (2000), Sato (2001), Carvalho (2000), Mendonça (2003) entre outros autores, apontam para a necessidade de que haja um comprometimento verdadeiro perante essas discussões.

É nesse sentido que algumas atividades práticas de educação ambiental passam por críticas como as que Michele Sato aponta:

\footnotetext{
${ }^{7}$ Nidelcoff (1979), ao explicar o que é Estudo do Meio, coloca que Meio é a realidade física, biológica, humana que nos rodeiam e que se ligam de maneira direta por meio da experiência; e quanto ao Estudo, comenta que este pode apresentar valores e gradações diferentes: aproximar-se afetivamente, descobrir coisas, exprimi-las, explicá-las, analisá-las.

${ }^{8}$ Segundo Pontuschka (1994), um estudo do meio pode variar "desde uma saída de estudantes e professores" com o objetivo de entretenimento, até "trabalhos interdisciplinares que demandam pesquisas de campo, bibliográfica, iconográfica", levando a um investimento/necessidade de trabalho tanto individual quanto coletivo.
} 
Proliferam-se, assim, ações pontuais de abraçar árvores ou oficinas de reciclagem de papel, sem nenhuma postura crítica dos modelos de consumo vivenciados pelas sociedades, ou pela análise do modo de relação dominadora do ser humano sobre a natureza, com alto valor antropocêntrico. (SATO, 2001, p. R-16)

Se, de um lado, o simples abraçar árvores não conduz a uma análise do modo de relação dominadora sobre a natureza, pode promover uma compreensão profunda (não analítica, não racional, mas perceptiva, experiencial) do que significa não dominar, do que significa estar integrado. E, além disso, do bem-estar - perceptível - quando da compreensão de que existem outras possibilidades a serem exploradas, estando em um ambiente menos impactado, numa relação dialética entre corpo, mente e espírito.

Com um questionamento pertinente sobre outras práticas educacionais, Carvalho (2000) questiona a transmissão de informações por educadores que utilizam as trilhas de interpretação, em geral, com grande peso para os conhecimentos vindos da Biologia, como o funcionamento dos ecossistemas e as interações entre os elementos da natureza. Ressalta que a "tradição explicativa das ciências naturais" se contrapõe a uma "ação interpretativa e via compreensiva de acesso ao meio ambiente", que indicariam um caminho para uma educação ambiental de perspectiva filosófica hermenêutica. "Educar, compreender, tornam-se desde uma perspectiva hermenêutica, uma aventura onde o sujeito e os sentidos do mundo vivido estão se constituindo mutuamente da dialética da compreensão/interpretação" (CARVALHO, 2000 , p. 8).

Sendo assim, acredita-se no potencial do uso dos EM para a relação de ensinoaprendizagem, visando criar, fortalecer laços e vínculos - objetivos e subjetivos - que contribuam tanto para a compreensão da realidade quanto para a consolidação do sentimento de pertença nos indivíduos, numa perspectiva de emancipação sociopolítica em prol de um projeto de felicidade.

Os estudos do meio, até hoje, foram mais utilizados no ensino da Geografia; mas outras disciplinas, como, por exemplo, Biologia, História, Ciências, Matemática, Literatura, utilizam-nos como estratégia de ensino-aprendizagem (PONTUSCHKA, 1994; DEBESSEARVISET, 1985; NIDELCOFF, 1979), com bastante sucesso entre docentes e discentes.

Considerando-se determinado território, os estudos do meio podem acontecer desde o entorno mais próximo dos estudantes - observações a partir do próprio corpo; e, num caracol imaginário, ir se expandindo para: a sala de aula, o prédio (ou local dos estudos), o jardim ou o espaço em volta, o quarteirão que abriga a escola e os adjacentes, o bairro e comunidades nele envolvidas e, assim por diante, até onde o fôlego e entusiasmo ou a necessidade indiquem como adequados e oportunos. "Qualquer pessoa pode fazer uma expedição no quintal da própria casa ou no jardim mais próximo. O que distingue, porém, uma expedição de um simples passeio é o fato de termos, no primeiro caso, um objetivo: o de conhecer" (BRANCO, 1984, p. 5).

Um estudo do meio pode ser caracterizado como um método - na medida em que permite ao estudante observar, descobrir, documentar, utilizar diferentes meios de expressão, desenvolvendo, assim, um espírito de síntese; ou como técnica pelo seu valor informativo em diferentes áreas do conhecimento, de forma não "livresca", por meio da experiência vivida, 
como aponta Magaldi (1994, apud PONTUSCHKA, 1994). No entanto é importante se utilizarem estratégias e vivências específicas que favoreçam as relações interpessoais e intrapessoais.

Nidelcoff (1979) considera que o estudo do meio pode ser "integral" ou "parcial". No primeiro caso, exemplifica como "o estudo de uma população, de um bairro, de uma cidade, sob todos os seus aspectos", e ressalta que este é um trabalho mais difícil, que requer "ação coordenada de várias equipes, durante bastante tempo"; na outra possibilidade, de um estudo parcial, sugere um "recorte" ou apenas um aspecto de um tema, por exemplo: o estudo da localização e instalações de uma fábrica, os hábitos alimentares de uma população, entre outros (NIDELCOFF, 1987, p. 12-3).

Para complementar a idéia de estudo do meio, supracitada, cabe mencionar que:

El estúdio de los médios geográficos, a través del análisis de las situaciones complejas a partir de todos los factores implicados: tiempo, espacio, fuerzas económicas y financieras, es una orientación intelectual, un verdadero estruturalismo. Obligando a pensar "juntas", causas múltiples y no siempre suficientes, ejerce una dialética que ya no puede confundirse con la demonstración matemática ni con la comprensión literaria. (DEBESSE-ARVISET, 1985, p. 169-70)

É o que Larosa Bondía chama de dar sentido à experiência, "sobretudo dar sentido ao que somos e ao que nos acontece", e discute os termos "informação", "conhecimento" e "aprendizagem", pois conhecimento e sabedoria passam pela quantidade de informação ou uma opinião que se tem sobre algo. A importância da experiência, na citação de Bondía, remete e reforça além do modo de ser/viver experienciado, à necessidade do "momento de parada":

A experiência, a possibilidade de que algo nos aconteça ou nos toque, requer um gesto de interrupção, um gesto que é quase impossível nos tempos que correm: requer parar para pensar, parar para olhar, parar para escutar, pensar mais devagar, olhar mais devagar, e escutar mais devagar; parar para sentir, sentir mais devagar, demorar-se nos detalhes, suspender a opinião, suspender o juízo, suspender a vontade, suspender o automatismo da ação, cultivar a atenção e a delicadeza, abrir os olhos e os ouvidos, falar sobre o que nos acontece, aprender a lentidão, escutar aos outros, cultivar a arte do encontro, calar muito, ter paciência e dar-se tempo e espaço. (BONDÍA, 2001, p. 5)

Para Tuan (1983), a experiência pode ter a conotação de passividade, pelo que uma pessoa suportou, tem sofrido ou aprendido com os acontecimentos. Mas experienciar é também aprender com base na própria vivência, atuar e criar a partir de dados, apesar de não se poder conhecer sua essência, "o que pode ser conhecido é uma realidade que é um constructo da experiência, uma criação de sentimento e pensamento". Então, pode-se depreender que, 
para experienciar, atuar e criar a partir de dados, como nos indica Tuan, é necessário o "gesto de interrupção", a que se refere Bondía, para completar os processos cognitivos.

Partir de la observación del entorno es un ejercicio de atención, de la aptitud para distinguir lo esencial de lo contingente; una incitación a imaginar comparaciones verificadores, esbozo de generalidad. Cada uno descubre los efectos de su propia acción en este medio físico, biológico, humano, y su poder a veces destructivo, así como la posibilidad de una belleza nueva. (DEBESSE-ARVISET, 1985, p. 161)

Nos estudos do meio, o exercício de observação e atenção deve ser adequado à faixa etária do grupo, bem como as atividades e temas coerentes com a proposta pedagógica do ensino básico à pós-graduação. É importante o comprometimento, a responsabilidade e o envolvimento do coletivo no estudo. Sem giz, quadro-negro ou carteiras, o estudo do meio torna-se um momento especial, único, pela oportunidade de se inovarem metodologias de ensino - aprendendo-se em outros ambientes, mas não só. Os estudantes, via de regra, sentemse mais "soltos", ficam mais entusiasmados, participam, se expõem com comentários e observações, despertando a atenção também do educador "aprendente". A paisagem - urbana e/ou rural - é mais do que apenas um cenário. Os estudantes, educadores e cidadãos/moradores, são pessoas que se expõem ao compartilharem, socializarem, indagarem, pesquisarem.

O conhecimento se adquire através da observação prolongada de cada objeto: animal, vegetal ou mineral; da comparação com os demais objetos; do acompanhamento demorado e paciente do seu modo de ser, de viver, de relacionar-se com o meio, com os outros seres, com os elementos e fenômenos da natureza. É, realmente, enxergar o mundo que nos cerca. (BRANCO, 1984, p. 6)

É importante observar a mudança de comportamento em relação àquele que os estudantes normalmente têm em sala de aula. É possível que isso se deva a outras habilidades que são estimuladas nesses eventos. Assim, um estudante mais "inquieto e falante" pode ser um bom interlocutor, vindo a motivar e agregar a turma; uma aluna mais tímida pode revelar-se uma excelente observadora de pássaros e insetos, contribuindo para um contato afetivo e efetivo com outras fronteiras do conhecimento.

Pensando-se em contribuir para a construção de sociedades com pessoas mais conscientes sobre a importância de se conhecer, respeitar e conservar a natureza, os estudos do meio, de modo geral, destinam-se à aplicação de alguns recursos didáticos fora da sala de aula, utilizando-se a natureza ou o ambiente "extraclasse" como espaço pedagógico, mais do que um "laboratório vivo", de forma a contribuir, em última instância, para a discussão da problemática ambiental.

As atividades de campo são os laboratórios onde se concretizam, emergem e interagem os conteúdos teóricos, elaborados em sala de aula, com a realidade concreta das transformações da natureza. É o 
local onde se confrontam os valores exibidos dentro de "quatro paredes" com os praticados nas atividades de campo. (TAMAIO, 2002, p. 93-4)

O propósito de um estudo do meio deve ser (e estar) bem claro, definido e detalhado, tanto para os proponentes (professores, direção, coordenadores, guias) quanto para os estudantes. Nesse sentido, algumas perguntas podem ajudar: Qual (quais) o(s) objetivo(s) do estudo? A quem se destina? Qual a duração? Quais as maiores dificuldades ou limites?

Para os proponentes, há, no mínimo, dois caminhos que devem ser percorridos concomitantemente: o "pedagógico" e o "logístico".

O "logístico" compreende tudo o que diz respeito ao planejamento e realização da saída em si: transporte, trajeto, agendamento de horários, alimentação, primeiros socorros, entre outros. É importante fornecer algumas orientações sobre roupas e alimentos mais adequados, cuidados com objetos de uso pessoal (máquina fotográfica, medicamentos etc), detalhar e verificar cada item e, por segurança, deve-se manter o que foi acordado, isto é, evitar mudar - aleatoriamente - um roteiro preestabelecido no "meio do caminho". As decisões tomadas no coletivo geralmente têm mais credibilidade e geram confiança para o desempenho dos trabalhos no campo.

A necessidade de realizar um estudo do meio pode surgir dos próprios estudantes, ou então ser prevista dentro do planejamento ou do projeto político pedagógico da escola. Dependendo da complexidade da saída, o ideal é que a apresentação dos conteúdos curriculares se inicie com alguma antecedência, na sala de aula, para o envolvimento e motivação, visando estimular a noção de responsabilidade e firmar os compromissos entre os estudantes.

É imprescindível que, a partir de um projeto, se construa um roteiro que auxilie a sistematização das anotações e observações, dos comentários pessoais, dos dados históricos, geográficos, socioeconômicos, desenhos/croquis, pequenas entrevistas, horários previstos, etc. Este roteiro, que pode ser um guia de campo, caderno de anotações ou diário de bordo, serve como um orientador, uma "base de dados" tanto para o educador quanto para os estudantes utilizarem antes, durante e após o "evento"; pois envolve pesquisa, organização, memória das questões investigadas, possibilita a seleção de informações, facilita a comparação entre os dados levantados e os conhecimentos de outros pesquisadores, e pode ser fonte das interpretações pessoais, lembranças e conclusões.

Uma saída pode ser utilizada para várias atividades/momentos diferenciados. Desta forma podem-se conjugar as "tarefas" que os estudantes deverão realizar com as atividades de socialização e/ou percepção. Eles podem estar todos juntos assistindo uma palestra, e depois, em grupos, entrevistando/conversando com pessoas, e num outro momento (num solo, por exemplo), cada um individualmente fazendo sua "síntese histórica" ou memória do dia.

A compreensão deste mundo passa, evidentemente, pela compreensão das relações que ligam o ser humano ao seu meio ambiente. Não se trata de acrescentar uma nova disciplina a programas escolares já sobrecarregados, mas de reorganizar os ensinamentos de acordo com uma visão de conjunto dos laços que unem homens e mulheres ao meio ambiente, recorrendo às ciências da natureza e às ciências so- 
As contribuições a partir do olhar atento: ...

ciais [...] numa perspectiva de uma educação que se estenda ao longo de toda a vida. (DELORS, 2000, p. 47)

A idéia de se usarem estudos do meio parece estar sintonizada com os quatro pilares da educação, que constituem uma via do saber, pelos "múltiplos pontos de contato, de relacionamento e de permuta" entre eles:

Aprender a conhecer, isto é, adquirir os instrumentos da compreensão; aprender a fazer, para poder agir sobre o meio envolvente; aprender a viver juntos, a fim de participar e cooperar com os outros em todas as atividades humanas; finalmente aprender a ser, via essencial que integra as três precedentes. (DELORS, 2000, p. 90)

Cada estudo do meio deve, portanto, ser minuciosamente planejado, organizado, detalhado, aproveitado, pois é único, experiência única, e como aprendizado, requer um gesto de interrupção, pois é impossível de ser repetido. É um tempo de disponibilidade e abertura para aprender sobre si mesmo, o outro, o mundo.

\section{Olhares acerca do estudo do meio}

É alegre e instrutivo passear por entre uma vegetação que nos é estranha. Em meio às plantas habituais ou a objetos que conhecemos de longa data, não pensamos coisa alguma, e de que vale a contemplação sem a reflexão?. (GOETHE, 1999, p. 71)

É difícil precisar quando as excursões/expedições com caráter didático começaram a surgir. Talvez tenham se forjado como espaço de aprendizagem paralelo às viagens dos naturalistas/exploradores atentos que, percebendo a riqueza e diversidade dos sistemas naturais como fonte de conhecimento, tinham, nos auxiliares dos trabalhos de campo, os seus aprendizes. Entre alguns dos que vieram ao Brasil no séc. XIX, para ver e estudar paisagens, podemse citar: Alexander von Humboldt, Auguste de Saint-Hilaire e Carl Philipp von Martius.

$\mathrm{Na}$ Europa, Goethe, por exemplo, contratou um jovem artista para retratar tudo o que lhe interessava, das paisagens às expressões humanas, como relata na sua obra "Viagem à Itália". Faz crer que aprimorou seus conhecimentos em diferentes áreas do conhecimento: Geologia, Botânica, Zoologia e Antropologia, no percurso que fez desde a Alemanha, entre 1786 e 1788, pois descreve lugares, solos, rochas, construções, costumes e culturas que encontrou pelo caminho. Pela sua narrativa, fica nítido o seu interesse científico pelas coisas, mas sobretudo deixa transparecer a emoção e percepção que tinha dos lugares, das pessoas e cenários pelos quais passava.

Alguns textos da literatura brasileira, apesar de menos conhecidos, indicam uma "concepção ideológica", que ressalta a importância de atividades educativas utilizando-se o espaço natural. Considerando-os, portanto, bastante apropriados para esta discussão, alguns trechos serão destacados, comentados e apresentados a seguir ipsis litteris. 
Num artigo da revista editada pelo Instituto de Botânica de São Paulo, "Resenha Historica", datado de abril de 1937, o botânico alemão F.C. Hoehne expressa suas idéias indicando a necessidade de propostas de programas instrutivos - com participação popular que valorizem o interesse, o entusiasmo e o gosto pela flora brasileira nas "escolas primárias e superiores [...] onde o povo pode buscar conhecimentos e receber emulações para o estudo da botânica" (HOEHNE, 1937, p. 66). O cientista e pesquisador comenta sobre a necessidade de se cultivar o senso "esthético", promover o amor ao estudo da flora e da natureza e "instruir o homem no caminho da verdade". Vai além, quando afirma que "já é tempo de se modificar a velha rotina do ensino da botânica", que precisa ser apresentada como ciência recreativa, útil e atraente, pois só a teoria cansa e desanima o estudante.

Ao descrever a coleção do Museu Paulista, Hoehne faz sugestões ousadas para a época, como de se produzir um "desenho animado" sobre orquídeas. Organizou programas de rádio com "conferências sobre a natureza brasílica", incentivou e promoveu a realização de cursos de aprendizagem para coleta e preparo de materiais para o herbário, entre outras ações. A sua preocupação e crítica ao modelo de educação praticado na época se destacam também neste trecho:

O Brasil, que ainda póde se ufanar da sua bella natureza, deveria abrir esta nova picada de progresso da cultura e reforma no ensino de botanica. Se tem tão poucos cultores e estudiosos da scientia amabilis, isto é devido, principalmente, não à carência de interesse do brasileiro pela natureza, mas ao defeituoso processo de ensino. (HOEHNE, 1937, p. 71)

Ele faz uma reflexão sobre a necessidade de mudança de hábitos e convenções sociais do povo, a necessidade de persistência e não violência para se alcançarem as reformas de costumes, assim, dá ênfase ao "amor para tudo que é natural do paiz". Valoriza a emoção ao se ter contato com a natureza, pois muitos "podiam passar por uma floresta sem sentir qualquer emulação para amar a terra". Cabe ainda destacar, do texto, um trecho que fala por si:

"Zurek zur Natur" (volta para a natureza) exclama o allemão e procura, no torrão transformado pela agricultura e industria, aquillo que a sua alma deseja. Contacto com aquillo que o Creador fez e em cujo meio o lançou é a felicidade do ser humano, porque a natureza é um lenitivo e estimulo ao mesmo tempo. Nas urbs, onde a vida se consome como o lubrificante e vapor de uma machina com os attrictos e o extinguir do fogo, o homem estiola-se como a flor sem orvalho e sem chuva. Os povos mais cultos compreendem a necessidade do contacto com a natureza. (HOEHNE, 1937, p. 74)

O cientista destaca a importância da Estação Biológica do Alto da Serra de Paranapiacaba, que pertencia, então, ao governo do estado, tanto no que se refere a figuras ilustres que a visitavam, como às trilhas que davam condições para longas caminhadas na mata. "Têm acesso os verdadeiros amigos da natureza, os que se deleitam em estudar a oecologia e mutua 
dependencia dos seres, os que apreciam a natureza assim como ella é sem a intromissão do homem" (HOEHNE, 1937, p. 82).

O contato e a apreciação da natureza também motivaram os trabalhos de outros grupos, como, por exemplo, o dos escoteiros. No Brasil, desde o início do séc. XX, eles foram incentivados a realizar suas atividades num contato íntimo com o meio natural, caminhando alertas e cautelosos, observando pegadas, se orientando com facilidade por meio do sol, das estrelas ou com o auxílio de bússolas.

A floresta é a escola da vida selvagem, escola que desenvolve no escoteiro a coragem, a tenacidade, o sangue frio, o espírito de observação, habituando-o a estar sempre alerta aos perigos que o podem rodear. É uma escola completa e encantadora. (LOBO, 1932, p. 23)

A compreensão de que por meio de um contato com a natureza podem-se desenvolver habilidades/virtudes é destacada no trecho em que Lobo comenta:

O mais interessante não é a observação de animaes prisioneiros ou da natureza morta, mas a observação dos animaes e da propria natureza, em toda a sua plenitude de liberdade e vida. Ahi é que as qualidades de coragem, paciencia, intelligencia e sagacidade do bom escoteiro se manifestam. (LOBO, 1937, p. 165)

O relato sobre estar ao ar livre continua com dicas para se seguir um animal sem ser pressentido, como estudar seus hábitos alimentares, onde e como se abrigam, como criam os filhotes, entre muitas outras. A obra não se restringe só à vida no campo, o treinamento do escoteiro passa também pela vida nas cidades, observação de pessoas, ruas, casas; atentos ao que está perto e longe.

É surpreendente a diversidade de jogos descritos no manual do escoteiro do Velho Lobo, podendo, pelo seu conteúdo, ser considerado também como precursor do movimento ambientalista; com nomes como "jogos de observação e memória”, "estudo da natureza", "ao ar livre" e "educação dos sentidos", as atividades explicitam uma intenção de contato direto, de apenas estar, compartilhar e aprender com a natureza.

Segundo Pontuschka (1994) os estudos do meio no Brasil começaram a ser utilizados nas escolas anarquistas, que seguiam a pedagogia de Francisco Ferrer, e tinham a intenção de "fundar escolas livres, independentes do Estado, alfabetizando adultos e crianças num espaço de debate e diálogo, levando-os 'a pensar com suas próprias cabeças"' (PONTUSCHKA, 1994 p. 165). Para a autora, esta concepção contrapunha-se aos ideais dos empresários, que, no início do séc. XX - portanto, da industrialização no Brasil - não sentiam necessidade de alfabetizar o trabalhador.

Os filhos das classes mais abastadas iam às escolas, enquanto os filhos dos operários trabalhavam para ajudar os pais. Faziam parte dessas escolas não só os imigrantes italianos, mas também os espanhóis, portugueses e brasileiros. 
O estudo do meio feito por tais escolas objetivava que os estudantes observando, descrevendo o meio do qual eram parte integrante poderiam refletir sobre as desigualdades, injustiças e promover mudanças na sociedade no sentido de saná-las. A escola livre estava muito vinculada ao conjunto dos movimentos sociais, políticos e culturais dos anarquistas, sempre no sentido de denúncia contra as arbitrariedades do Estado e da Igreja contra os trabalhadores adultos e crianças. (PONTUSCHKA, 1994, p. 168)

Outras personalidades contribuíram para a divulgação de idéias e ideais visando uma educação popular fundamentada no respeito individual e coletivo, na promoção da autonomia, na liberdade de expressão: o brasileiro Paulo Freire (1921-1997), o francês Célestin Freinet (1896-1966), o ucraniano Anton Makarenko (1888-1939), e o croata Rudolf Steiner (18611925), com a pedagogia Waldorf.

Os estudos do meio realizados pelas escolas tradicionais, com exceção, talvez, daquelas que adotam a metodologia Waldorf, infelizmente, têm uma preocupação longínqua com o desenvolvimento do espírito, abordagem tida como esotérica e, portanto, desprovida de validade científica. No entanto é de seres humanos que estamos falando quando elaboramos essas atividades e, nessa perspectiva, que perda para o desenvolvimento de nossos alunos significa essa visão materialista do mundo! (MENDONÇA, NEIMAN, 2003, p. 48)

Mendonça e Neiman (2003) afirmam que os estudos do meio surgiram como atividade organizada em algumas escolas nas décadas de 1950 e 1960, ganhando força em várias instituições de ensino a partir da década de 1970. Os autores apontam/associam, ainda, outros educadores e suas correntes/propostas pedagógicas que influenciaram o desenvolvimento desta atividade: Jean Piaget (1896-1980); Lev Vygotsky (1896-1934); Howard Gardner (1945), principalmente lembrando que a própria epistemologia do conhecimento estava sendo construída/investigada.

Parece ser possível afirmar que os autores apresentados, ou pelo menos algumas das suas intenções/idéias, tenham também a sua contribuição no sentido de fomentar o movimento ambientalista, pois além de enfatizarem/estimularem a aproximação à natureza de maneira cordial, amistosa, como a de um aprendiz - categoria a que todos os seres humanos pertencem - suas propostas embutem, na educação, uma ação político-libertadora.

\section{Considerações finais}

A importância de se realizarem atividades extraclasse, denominadas de estudos do meio, é referendada pela contribuição para a melhoria da relação de ensino-aprendizagem, entre outros ganhos, objetivos e subjetivos, mensuráveis e imensuráveis. Mesmo diante desse 
reconhecido potencial, deve-se lembrar das dificuldades operacionais e curriculares das escolas para incentivar e realizar tais atividades.

Quando inserido num projeto político-pedagógico, o EM comprometido, bem estruturado, pode promover um contato entre os participantes, a realidade e o entorno com a devida qualidade, já que o modo de vida contemporâneo nos afasta de uma percepção crítica.

Utilizados em plena função, os órgãos sensórios interpretam estímulos e dão um alerta, ou, em caso contrário, podem metaforicamente estar envoltos de "nuvens escuras", que "embotando-os", imobilizam e alienam os seres humanos. Os sentidos - tato, olfato, audição, paladar e visão - poderiam (e deveriam) servir como proteção ou defesa às agressões externas, mas também como aprendizado, deleite, contemplação.

Podendo ser realizado até em espaços urbanos, ressalta-se a importância de se incentivar, no EM, a aproximação a ambientes menos antropizados, buscando-se também contemplação e fruição, pois contatos superficiais com a natureza pouco têm de autênticos. A necessidade de aproximação/contato físico direto é reforçada por Yi-Fu Tuan:

$\mathrm{Na}$ vida moderna, o contato físico com o próprio meio ambiente natural é cada vez mais indireto e limitado a ocasiões especiais. Fora da decrescente população rural, o envolvimento do homem tecnológico com a natureza é mais recreacional do que vocacional. O circuito turístico, atrás das janelas de vidro raiban, separa o homem da natureza. (TUAN, 1980, p. 110)

É importante lembrar que o conceito de natureza se modifica em função do espaço, da cultura e do tempo; sendo fruto de uma construção/conhecimento que ainda está se processando no ocidente, que ora a distancia, ora a aproxima do ser humano. De qualquer modo, somos parte intrínseca dela. Vivemos numa época de reconhecer, relembrar a necessidade que temos do mundo natural, da frágil intimidade com esses ambientes.

Um estudo do meio, hoje em dia, para seres urbanizados, industrializados e globalizados que somos, precisa ser dirigido de forma suave, porém firme, para que os participantes resgatem, inclusive, sua capacidade de se espantarem, de acolherem o silêncio, de sentirem a solitude, a diversidade, o contato com o outro e, sobretudo, com o belo, o ético e o estético - uma relação quase desconhecida na atualidade.

A realização de estudos do meio precisa ser estimulada apesar das dificuldades econômicas, pedagógicas e estruturais enfrentadas pelas instituições de ensino hoje em dia. É uma técnica que precisa ter, como premissa, ensinar com responsabilidade, dinamismo, entusiasmo, resgatando-se o maravilhamento pelo aprender, pela vida. 
Lestinge, S.; Sorrentino, M.

\section{Referências}

BONDÍA, J. L. Notas sobre a experiência e o saber de experiência. 2001. Disponível em: <http://www.anped.org.br/rbe19/03-bondia.pdf>. Acesso em: 18 out. 2007.

BRANCO, S. M. Expedição ecológica ao fundo do quintal. São Paulo: CETESB, 1984.

BRANDÃO, C. R. O ambiente, o sentimento e o pensamento: dez rascunhos de idéias para pensar as relações entre eles e o trabalho do educador ambiental. In: FÓRUM DE EDUCAÇÃO AMBIENTAL, 4., 1997, Rio de Janeiro. Anais... Rio de Janeiro, 1997. p. 17-38.

CAPRA, F. A teia da vida: uma nova compreensão científica dos sistemas vivos. São Paulo: Cultrix, 1996.

CARVALHO, I. Qual educação ambiental? Elementos para um debate sobre educação ambiental popular e extensão rural. Agroecologia e Desenvolvimento Rural Sustentável, Porto Alegre, v. 2, n. 2, 2001.

. Los sentidos de lo "ambiental": la contribuición de la hermenéutica a la pedagogía de la complejidad. In: LEFF, E. (Org.). La complejidad ambiental. México: Siglo Veintiuno, 2000. p. 85-105.

DALLARI, D. Direito de participação. In: SORRENTINO, M. (Org.). Ambientalismo e participação na contemporaneidade. São Paulo: Ed. EDUC, 2001. p. 85-114.

DEBESSE-ARVISET, M. L. El entorno en la escuela: una revolución pedagógica: didática de la geografia. 3. ed. México: Ediciones Roca, 1985.

DELORS, J. Educação: um tesouro a descobrir. 4. ed. São Paulo/Brasília: Cortez/MEC: Unesco, 2000.

DEMO, P. Avaliação qualitativa. 7. ed. Campinas: Autores Associados, 2002.

FREIRE, P. Pedagogia da autonomia. 14.ed. São Paulo: Paz e Terra, 2000.

GOETHE, J. W. Viagem à Itália. São Paulo: Companhia das Letras, 1999.

HILLMAN, J. Cidade e alma. São Paulo: Studio Nobel, 1993.

HOEHNE, F. C. Programa instructivo e educativo. Resenha Historica, p. 67-82, 1937.

LESTINGE, S. Olhares de educadores ambientais para estudos do meio e pertencimento. 2004. 247f. Tese (Doutorado em Recursos Florestais) - Escola Superior de Agricultura "Luiz de Queiroz", Piracicaba, 2004.LOBO, V. Guia do escoteiro. 2. ed. Rio de Janeiro: Imprensa, 1932.

MENDONÇA, R.; NEIMAN, Z. À sombra das árvores: transdisciplinaridade e educação ambiental em atividades extraclasse. São Paulo: Chronos, 2003.

MORIN, E. Educar na era planetária. São Paulo: Cortez/Unesco, 2003.

. Os sete saberes necessários à educação do futuro. São Paulo: Cortez/

Unesco, 2000. 
As contribuições a partir do olhar atento: ...

NIDELCOFF, M. T. A escola e a compreensão da realidade. São Paulo: Brasiliense, 1979.

OT'T, M. B. Ensino por meio de solução de problemas. In: CANDAU, V. M. (Org.). A didática em questão. Petrópolis: Vozes, 1989.

PONTUSCHKA, N. N. A formação pedagógica do professor de geografia e as práticas interdisciplinares. 1994. 343f. Tese (Doutorado em Educação) - Faculdade de Educação, Universidade de São Paulo, São Paulo, 1994.

SANTOS, B. S. Um discurso sobre as ciências. 13. ed. Porto: Afrontamento, 2002.

SATO, M. Debatendo os desafios da educação ambiental. Disponível em: < http:// www.ufmt.br/gpea/pub/DesafiosEA.pdf>. Acesso em: 18 out. 2007.

SERRES, M. O contrato natural. Porto Alegre: Instituto Piaget, 1994.

TAMAIO, I. O professor na construção do conceito de natureza: uma experiência de educação ambiental. 1. ed. São Paulo: Annablumme/WWF, 2002.

TUAN, Y. Espaço e lugar. São Paulo: Difel, 1983.

. Topofilia. São Paulo: Difel, 1980.

Artigo recebido em outubro de 2007 e aprovado em junho de 2008.

619

Ciência \&̊ Educação, v. 14, n. 3, p. 601-19, 2008 